\title{
Chitin degradation potential and whole-genome sequence of Streptomyces diastaticus strain CS1801
}

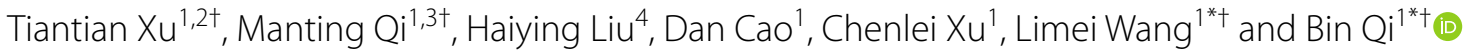

\begin{abstract}
The aim of this study was to evaluate the chitin degradation potential and whole-genome sequence of Streptomyces diastaticus strain CS1801, which had been screened out in our previous work. The results of fermentation revealed that CS1801 can convert the chitin derived from crab shells, colloidal chitin and N-acetylglucosamine to chitooligosaccharide. Additional genome-wide analysis of CS1801 was also performed to explore the genomic basis for chitin degradation. The results showed that CS1801 possesses a chromosome with 5,611,479 bp (73\% GC) and a plasmid with 1,388,284 bp (73\% GC). The CS1801 genome consists of 7584 protein-coding genes, 90 tRNA and 21 rRNA operons. In addition, the results of genomic CAZyme analysis indicated that CS1801 comprises 103 glycoside hydrolase family genes, which could regulate the glycoside hydrolases that contribute to chitin degradation. The whole-genome information of CS1801 could highlight the mechanism underlying the chitin degradation activity of CS1801, strongly indicating that CS1801 is characterized by a substantial number of genes encoding chitinases and the complete metabolic pathway of chitin, conferring CS1801 with promising potential applicability in chitooligosaccharide production.
\end{abstract}

Keywords: Chitin, Chitinase, Biodegradation, Whole genome, Crustacean waste utilization

\section{Introduction}

Chitooligosaccharide (COS) is a water-soluble polysaccharide obtained by treatment of chitin or chitosan with acid hydrolysis, enzymatic degradation or both (Einbu et al. 2007; Liu et al. 2009). Generally, COS is characterized by a degree of polymerization (DP) of less than 20 (Lee et al. 2002). COS performs many functions, such as antibacterial effects (Sun et al. 2018), antioxidant activity (Fang et al. 2015), and animal and plant growth promotion (Nandhini et al. 2017; Shenghe et al. 2017). COS has become a research topic of interest and has been widely

\footnotetext{
*Correspondence: wlmqb@126.com; qibin65@126.com

†Tiantian Xu and Manting Qi contributed equally to this work and should be considered cofirst authors

${ }^{\dagger}$ Limei Wang and Bin Qi contributed equally to this work

${ }^{1}$ Research Center of Fermentation Engineering, Changshu Institute

of Technology, Changshu 215500, China

Full list of author information is available at the end of the article
}

used in medicine (Zhao et al. 2017; Zhou et al. 2018), agriculture (Swiatkiewicz et al. 2015; Lan et al. 2016) and food (Cao et al. 2018; Jiang et al. 2018).

Chitin is an important precursor for the production of $\mathrm{COS}$ and a polymer of $\mathrm{N}$-acetylglucosamine (GlcNAc) linked by $\beta$-1,4-glycosidic bonds (Nguyen-Thi and Doucet 2016). Chitin is ubiquitous; its reserves are second only to those of cellulose, which is the second largest renewable resource on Earth, and approximately 10 billion tons of chitin is biosynthesized (Rinaudo 2006). The main raw material used in the industrial production of chitin is discarded shrimp and crab shells from aquatic processing plants. These shells contain more than $20 \%$ chitin (Hamdi et al. 2017). In China, due to the large number of lakes and the vast sea area, shrimp and crab resources are abundant. With the development of the Chinese seafood and farmed shrimp and crab industries, the amount of these wastes is increasing, causing serious environmental 
pollution and increasing the burden on businesses. However, these wastes are important resources.

At present, COS preparation is performed largely via a chemical method. Enzyme-assisted hydrolysis is a better method to obtain COS than chemical methods, with higher purity and lower pollution, but the search for proper enzymes remains ongoing (Liang et al. 2018).

Chitinase and chitosanase are promising enzymes for the production of COS, which has been reported in the literature (Kidibule et al. 2018; Zhang et al. 2018; Guo et al. 2019). The gene encoding chitosanase from Streptomyces albolongus was cloned, sequenced and expressed in Escherichia coli and shown to hydrolyze chitosan to primarily D-GlcN and chitobiose (Guo et al. 2019). To improve industrial chitosanase application, researchers have used carbohydrate-binding module fusion technology to efficiently immobilize GH46 chitosanase (Lin et al. 2019). The stability of the immobilized enzyme is superior to that of the natural enzyme, and three chitosan products with different molecular weights can be produced via the optimized reaction (Lin et al. 2019). However, chitosan has a general limitation as a substrate because it is not completely deacetylated, which results in a nonuniform degree of acetylation of the chitosanase hydrolysate. The single DP and the degree of acetylation of the product components have a strong effect on the identification of the activity of the bioactive components of COS. Two partially acetylated chitotrioses $(N$-acetylchitotriose and $N, N^{\prime}$-diacetylchitotriose) were produced to study the relationship between activity and acetylation. The antioxidant activities of two partially acetylated shell trisaccharides and virgin trisaccharides were further studied. $N, N^{\prime}$-diacetylchitotriose, with a high degree of acetylation, has the highest antioxidant activity ( Li et al. 2013). Furthermore, COS, with a 50\% degree of acetylation, was the most effective at alleviating salt stress in wheat seedlings (Zou et al. 2015). These results indicated that the activity of COS was closely related to its degrees of acetylation and polymerization.

However, despite the presence of the chitinase gene in bacterial and fungal genomes, the ability to hydrolyze insoluble chitin has been identified in only a few species, such as Serratia mucilis and Bacillus, Pseudomonas and Streptomyces species (Hara et al. 2013; Sorokin et al. 2014; Durairaj et al. 2017; Ilangumaran et al. 2017; Moon et al. 2017). Chitinase is a specific hydrolase that directly hydrolyzes chitin to produce fully acetylated COS. Salinivibrio sp. BAO-1801 was isolated from the fermentation broth of salted shrimp, and its chitinase was characterized (Le and Yang 2018). The main product of this enzyme is acetylchitobiose. The binding of different domains to insoluble chitin was studied by NMR spectroscopy (Takashima et al. 2018). The CBM18 domain hydrolyzed insoluble chitooligosaccharide better than the GH19 domain.

Although the chitinases produced by microorganisms have made significant contributions to the transformation of shrimp and crab shell wastes, their molecular and ecological roles in industrial applications have not been fully explored (Nazari et al. 2011). To study the degradation mechanism of enzymes with specific effects produced by microorganisms, whole-genome sequencing technology is widely used. Bifidobacterium choerinum FMB-1, which can degrade resistant starch, was subjected to whole-genome analysis, and 11 protein-coding genes related to $\alpha$-glucan degradation were found (Jung et al. 2018). Cellulase-producing Paenibacillus lautus BHU3 was subjected to whole-genome analysis, and 143 glycoside hydrolase $(\mathrm{GH})$ genes were discovered. These genes may play a vital role in enhancing cellulolytic attributes (Yadav and Dubey 2018).

Currently, few draft genome sequencing data sets are available for chitinase-producing strains capable of degrading insoluble chitin (Sorokin et al. 2014). Therefore, improving the pool of information via wholegenome sequencing analyses of different strains that produce chitinase will aid in elucidating the genomic basis of chitin decomposition activity and the utilization of degraded chitin. In our previous study, we selected a strain from fermented shrimp paste that could decompose chitin to COS and identified it as Streptomyces diastaticus CS1801 (Xu et al. 2019). In this study, wholegenome sequencing of the chitinase-producing S. diastaticus strain CS1801 was performed to describe specific genomic information regarding chitin degradation activity. The possibility of directly degrading shrimp and crab shells to produce COS was studied.

\section{Materials and methods}

\section{Determination of the ability of CS1801 to transform COS}

The bacteria were isolated from shrimp paste and stored in the China Center for Type Culture Collection (CCTCC, Wuhan, China). The isolate was classified as Streptomyces diastaticus CS1801, and the accession number is CCTCC No. M2018263. Using chitin colloid, GlcNAc or Chinese Eriocheir sinensis shell powder as the sole carbon source, the production of five kinds of COSs $(\mathrm{DP}=1-5)$ was evaluated in the fermentation broth of CS1801 with ultra-high-performance liquid chromatography-mass spectrometry (UPLC-MS, Waters, Massachusetts, United States) after 5 days of fermentation. To prepare the colloidal chitin, flaked chitin was shredded, and $10 \mathrm{~g}$ of chitin powder was slowly added to $200 \mathrm{~mL}$ of concentrated hydrochloric acid and stirred quickly. After the colloidal chitin was dissolved completely, the impurities were removed by glass cotton filtration, and 
the solution was added to $1000 \mathrm{~mL}$ of distilled water. A precipitate was obtained by centrifugation and washed with distilled water for neutralization. The fermentation medium was prepared as follows: solution A consisted of $1.4 \mathrm{~g} / \mathrm{L} \mathrm{K}_{2} \mathrm{HPO}_{4}, 0.6 \mathrm{~g} / \mathrm{L} \mathrm{KH}_{2} \mathrm{PO}_{4}, 1 \mathrm{~g} / \mathrm{L} \mathrm{MgSO}_{4} \cdot 7 \mathrm{H}_{2} \mathrm{O}$, $10 \mathrm{~g} / \mathrm{L} \mathrm{NaCl}$, and $20 \mathrm{~g} / \mathrm{L}\left(\mathrm{NH}_{4}\right)_{2} \mathrm{SO}_{4}$ in $1000 \mathrm{~mL}$ of deionized water at $\mathrm{pH} 6.5$, and solution $\mathrm{B}$ consisted of $10 \mathrm{~g} / \mathrm{L}$ sole carbon source at $\mathrm{pH}$ 6.5. The two solutions were mixed in equal volumes before use.

The standards were $0.1429 \mathrm{mg} / \mathrm{mL}$ GlcN, $0.1429 \mathrm{mg} /$ $\mathrm{mL}$ shell disaccharide $\left((\mathrm{GlcN})_{2}\right), 0.1429 \mathrm{mg} / \mathrm{mL}$ shell trisaccharide $\left((\mathrm{GlcN})_{3}\right), 0.1429 \mathrm{mg} / \mathrm{mL}$ shell tetrasaccharide $\left((\mathrm{GlcN})_{4}\right)$ and $0.1429 \mathrm{mg} / \mathrm{mL}$ shell pentasaccharide $\left((\mathrm{GlcN})_{5}\right)$. The COS standard product was purchased from Shanghai Huich Biotech Inc. The experimental conditions for UPLC-MS followed those published in an article by our laboratory in 2019 (Xu et al. 2019). The conversion rate was the ratio of the total COS concentration $(\mathrm{DP}=1-5)$ to the sole carbon source concentration.

$$
\text { Conversion rate }=\frac{\operatorname{COS}(\mathrm{DP}=1-5)(\mathrm{mg} / \mathrm{L})}{5000(\mathrm{mg} / \mathrm{L})} \times 100 \%
$$

\section{Whole-genome sequencing assembly}

Genomic DNA of S. diastaticus CS1801 was extracted using a Bacterial Genomic DNA Extraction Reagent Kit (Sangon Biotech, Bioengineering Biotechnology (Shanghai) Co., Ltd., Shanghai, China).

Sequencing was performed using an Illumina $\mathrm{HiSeq}^{\mathrm{TM}}$ second-generation sequencer (Illumina, Inc., Delaware, United States), and the linker sequences and low-mass bases in the reads were removed using Trimmomatic. Nonamplified long DNA fragments were sequenced using a PacBioRS II third-generation sequencer (PacBio, Pacific Biosciences of California, Inc., Delaware, United States). The linker sequences and low-mass bases in the reads were removed after sequencing and according to the estimated genome size. The data were pooled and analyzed until an estimated 40X coverage of the genome was obtained. Canu was used to splice three generations of single-molecule sequencing data, followed by secondgeneration sequencing data. The scaffold complement GAP was obtained by splicing with GapFiller, and finally, the sequence data were corrected by PrInSeS-G to modify editing errors and the insertion of small fragments during the splicing process.

\section{Homologous gene alignment}

The common genes and unique genes of CS1801 and its near-source strains were obtained by the pangenome analysis pipeline (PGAP) for further analysis. The genomic information and gene sequences of the nearsource strains are shown in Table 1. First, PGAP was used to collect the protein sequences of all strains for BLAST alignment. According to the BLAST alignment results, the similarity between different proteins was determined, and similar genes were assigned to same-ortholog clusters. A homologous gene present in all samples was used as a core gene. Then, the shared gene was removed, a nonconsensus gene was obtained, and the specific gene was a gene uniquely possessed only by the tested sample. All nonconsensus genes were combined with a consensus gene as a pangene. A phylogenetic tree was constructed based on the neighbor-joining clustering results from homologous genes and pangenome analysis.

Table 1 List of strains closely related to Streptomyces diastaticus CS1801

\begin{tabular}{|c|c|c|c|c|}
\hline Tax ID & Name & Assembly ID & Level & Distance \\
\hline 1638939 & Streptomyces sp. KE1 & ASM101459v1 & Contig & $5.9 e-03$ \\
\hline 463642 & Streptomyces sp. F-1 & Streptomyces_sp_F1_v3 & Scaffold & $7.9 e-03$ \\
\hline 579932 & Streptomyces sp. FXJ7.023 & Streptomyces sp. FXJ7.023 & Contig & $8.8 e-03$ \\
\hline 682181 & Streptomyces sp. SA3_actF & ASM17921v1 & Contig & $9.8 \mathrm{e}-03$ \\
\hline 1463876 & Streptomyces sp. NRRL F-6628 & ASM72145v1 & Contig & 0.01 \\
\hline 1428626 & Streptomyces malaysiense & ASM98088v2 & Contig & 0.01 \\
\hline 996637 & Streptomyces griseoaurantiacus M045 & ASM20460v1 & Contig & 0.01 \\
\hline 1286094 & Streptomyces aurantiacus JA 4570 & STRAU & Contig & 0.01 \\
\hline 889487 & Streptomyces sp. S4 & ASM29771v1 & Scaffold & 0.01 \\
\hline 42239 & Streptomyces sampsonii & ASM170419v1 & Complete genome & 0.01 \\
\hline 1463837 & Streptomyces sp. NRRL B-3253 & Doro.v1.0 & Scaffold & 0.01 \\
\hline 545123 & Streptomyces silaceus & ASM141974v1 & Scaffold & 0.01 \\
\hline 412968 & Streptomyces sp. M10 & ASM80053v1 & Scaffold & 0.01 \\
\hline 457425 & Streptomyces albus J1074 & ASM35952v1 & Complete genome & 0.01 \\
\hline 1571532 & Streptomyces sp. CNQ431 & GCF_000797385.1 & Complete genome & 0.01 \\
\hline
\end{tabular}




\section{Genome prediction and annotation}

Rapid prokaryotic genome annotation (Prokka) was used to predict the assembly results of the gene components, and the obtained genes were submitted to Clusters of Orthologous Groups (COG) of proteins (Tatusov et al. 2000), Gene Ontology (GO), and Kyoto Encyclopedia of Genes and Genomes (KEGG) databases (Kanehisa and Goto 2000) and compared to obtain functional annotation information.

\section{CAZy carbohydrase analysis}

The protein sequences inferred from the whole-genome sequence were aligned with the carbohydrate active enzyme (CAZy) database (http://www.cazy.org/) using HMMER3 to obtain the corresponding carbohydrateactive enzyme annotation information (Lombard et al. 2014). The screening condition was E-value $<1 \mathrm{e}^{-5}$.

\section{Drug resistance functional annotation}

The protein sequences inferred from the whole-genome sequence were compared with the Comprehensive Antibiotic Resistance Database (CARD) by BLAST (McArthur et al. 2013), and the annotation information for each gene and its corresponding drug resistance function was combined to obtain the annotation result.

\section{$\mathrm{NCBI}$ registration number}

The whole-genome sequence data of $S$. diastaticus CS1801 $(6.9 \mathrm{Mb})$ were deposited in the NCBI database with the accession number SUB5461644.

\section{Results}

\section{Analysis of $\operatorname{COS}$ conversion}

The fermentation broth with colloidal chitin as the sole carbon source contained $6.865 \mathrm{mg} / \mathrm{L}(\mathrm{GlcN})_{2}$, $10.949 \mathrm{mg} / \mathrm{L} \quad(\mathrm{GlcN})_{3}, \quad 15.603 \mathrm{mg} / \mathrm{L} \quad(\mathrm{GlcN})_{4}$, and
$20.833 \mathrm{mg} / \mathrm{L}(\mathrm{GlcN})_{5}$, and its total conversion rate was $1.085 \%$. The fermentation broth with GlcNAc as the sole carbon source contained $299.753 \mathrm{mg} / \mathrm{L} \mathrm{GlcN}, 5.010 \mathrm{mg} / \mathrm{L}$ $(\mathrm{GlcN})_{3}, 9.894 \mathrm{mg} / \mathrm{L}(\mathrm{GlcN})_{4}$, and $23.398 \mathrm{mg} / \mathrm{L}(\mathrm{GlcN})_{5}$, and its total conversion rate was $6.761 \%$. The fermentation broth with crab shell powder as the sole carbon source contained $1.670 \mathrm{mg} / \mathrm{L}(\mathrm{GlcN})_{3}, 5.988 \mathrm{mg} / \mathrm{L}$ $(\mathrm{GlcN})_{4}$, and $34.262 \mathrm{mg} / \mathrm{L}(\mathrm{GlcN})_{5}$, and its total conversion rate was $0.838 \%$. These results are summarized in Table 2.

\section{Complete genome of Streptomyces diastaticus CS1801}

Genome-wide analysis was performed to decipher the full set of genes involved in chitin degradation. The complete genome of $S$. diastaticus CS1801 is composed of two separated circular sequences: one is a 5,611,479-bp chromosome with a $73 \%$ GC content, and the other is a 1,388,284-bp plasmid with a $73 \%$ GC content (Fig. 1). The genome consists of 7584 protein-coding genes and 90 tRNA and 21 rRNA operons. The whole-genome sequence of Streptomyces diastaticus CS1801 was compared with that of a near-source strain, and the number of homologous genes was counted (Fig. 2a). Based on a comparative analysis of the ubiquitous gene set consisting of genes and nonconsensus genes, the genome has 2898 unique single genes, which is a much higher number than that of closely related strains. Phylogenetic tree analysis showed that S. diastaticus CS1801 is orthologous to related strains and that the strains are derived from a common ancestor (Fig. 2b). A total of 2633 unigenes were annotated in the COG database and were assigned to 14 functional groups (Fig. 3a). Among the groups, transcription (10.22\%), amino acid transport and metabolism (8.31\%), and carbohydrate transport and metabolism (7.42\%) were the most abundant, while the least enriched functional group was RNA processing and modification

Table 2 Results for transformation of COS by Streptomyces diastaticus CS1801

\begin{tabular}{|c|c|c|c|c|c|c|}
\hline \multirow[t]{2}{*}{ Carbon source } & \multirow{2}{*}{$\begin{array}{l}\text { Total conversion rate } \\
(\%)\end{array}$} & \multicolumn{5}{|c|}{$\cos (\mathrm{mg} / \mathrm{L})$} \\
\hline & & GIcN & $(\mathrm{GlcN})_{2}$ & $(\mathrm{GlcN})_{3}$ & $(\mathrm{GlcN})_{4}$ & $(\mathrm{GlcN})_{5}$ \\
\hline Colloidal chitin & 1.085 & 0 & 6.865 & 10.949 & 15.603 & 20.833 \\
\hline GlcNAC & 6.761 & 299.753 & 0 & 5.010 & 9.894 & 23.398 \\
\hline Crab shell & 0.838 & 0 & 0 & 1.670 & 5.988 & 34.262 \\
\hline
\end{tabular}

(See figure on next page.)

Fig. 1 Circular map of the Streptomyces diastaticus CS1801 genome. a Chromosome; b plasmid. From the outside to the inside: the first circle represents the COG database-annotated genes, with the color corresponding to the COG-annotated letter; the second circle represents RNA; the third circle is the GC content (the peak level reflects the GC amount), with the outer circle representing the sense chain and the inner circle representing the antisense chain; and the innermost circle reflects the asymmetry of the GC content 

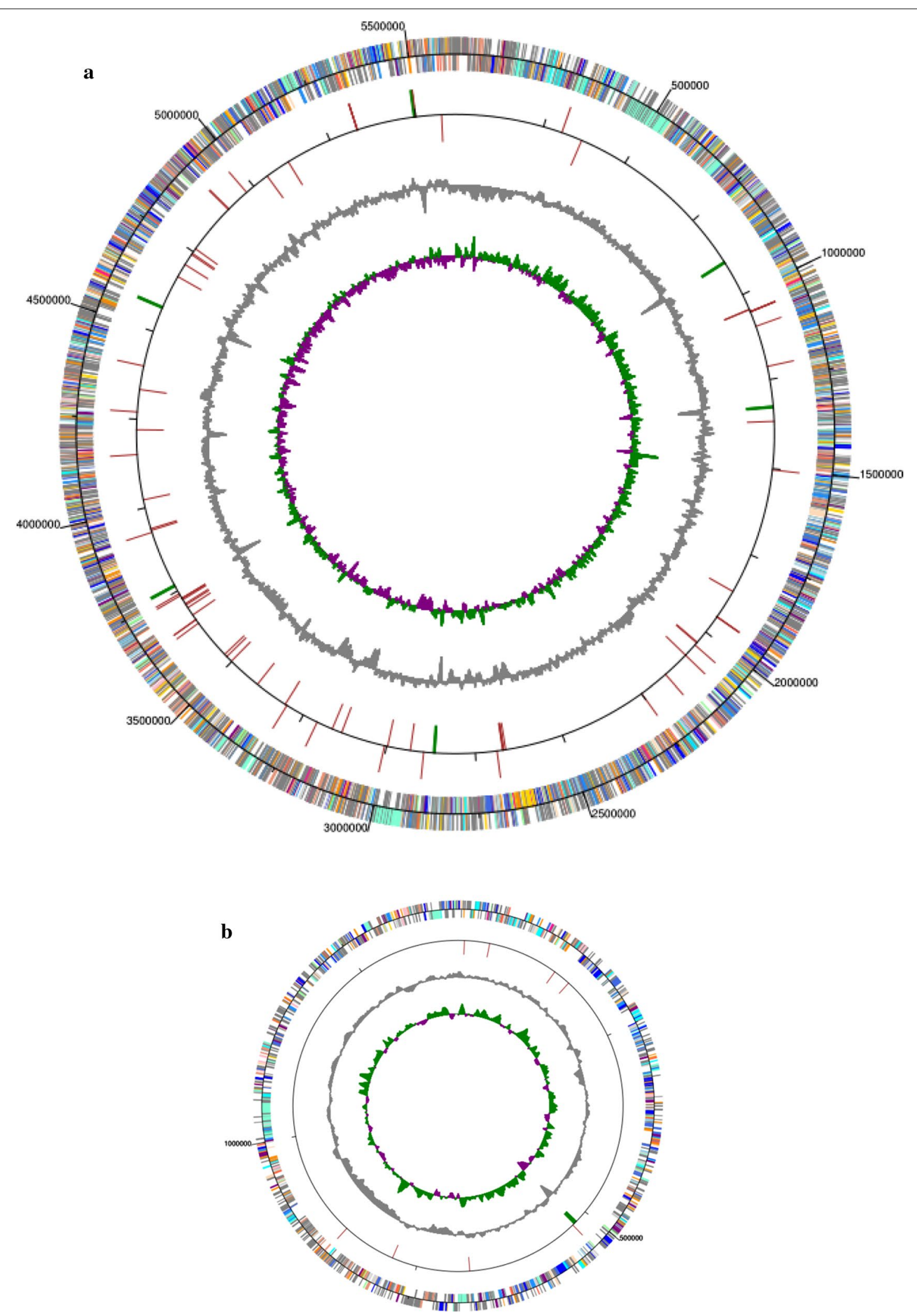

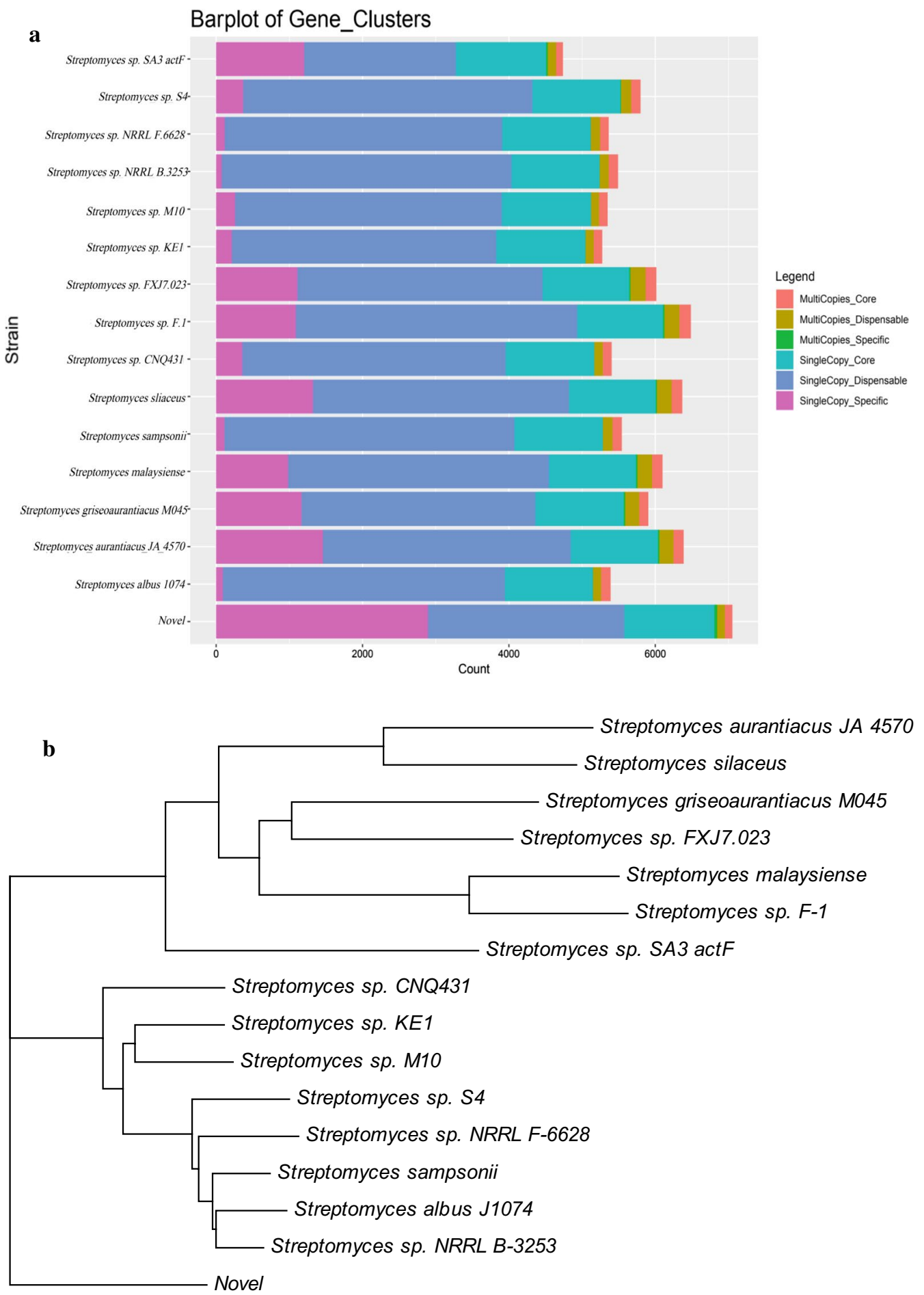

Fig. 2 a Histogram of the number of homologous genes. $\mathbf{b}$ Phylogenetic tree based on pangenes constructed by neighbor-joining clustering

$(0.03 \%)$. The genes in the carbohydrate transport and metabolism functional group are closely related to the degradation of chitin to COS. A total of 9865 unigenes were classified into the biological process category, 6963 unigenes were classified into the cellular component category, and 6656 unigenes were classified into the molecular function category (Fig. 3b). The largest functional groups in the biological process category were metabolic 

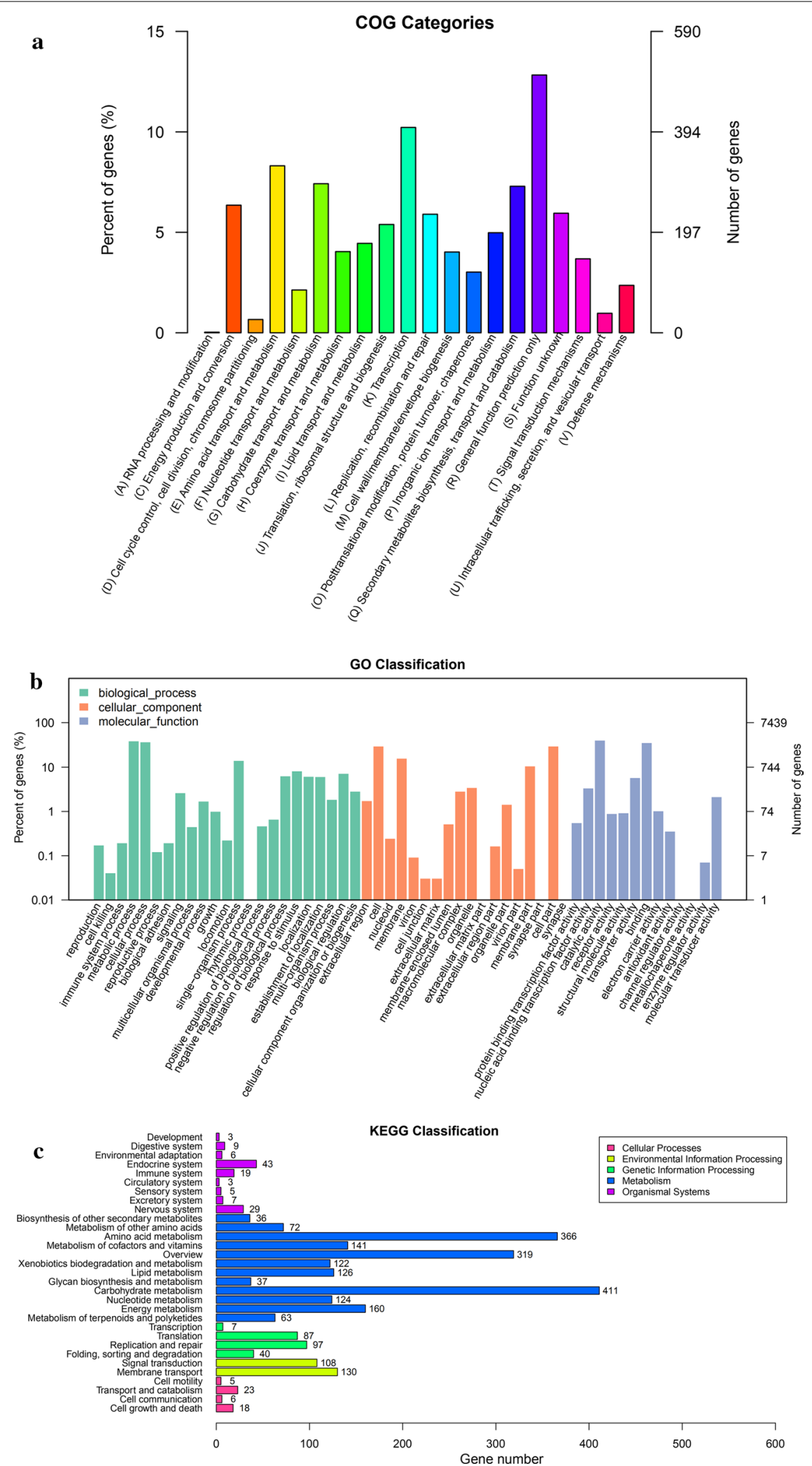

Fig. 3 a COG annotation distribution histogram; b GO annotation distribution histogram; c KEGG pathway classification histogram 
process and cellular process. In the cellular component category, the largest functional groups were cell and cell part, and the largest functional groups in the molecular function category were catalytic activity and binding. A total of 2667 unigenes were annotated in the KEGG database (Fig. 3c), of which 411 unigenes were classified as carbohydrate metabolism genes, 37 unigenes were classified as glycan biosynthesis genes, and 126 unigenes were classified as lipid metabolism genes.

\section{CAZy carbohydrase analysis}

The results (protein count) showed that CS1801 has 90 GHs, 54 glycosyl transferases (GTs), 53 carbohydrate esterases (CEs), 29 auxiliary activities (AAs), 22 carbohydrate-binding modules (CBMs) and 6 polysaccharide lyases (PLs). Extended CAZyme analysis indicated that the GH family was divided into $103 \mathrm{GH}$ subfamilies (Table 3). Among the GHs, the major subcategory was GH13, followed by GH15, GH18 and GH23. Chitinases are present mainly in GH18 and GH19 (Suma and Podile 2013). N-Acetylglucosaminidase can split the $\beta$-(1,4)-glycosidic bond of $N, N^{\prime}$-diacetylchitobiose $\left((\mathrm{GlcNAc})_{2}\right)$ to generate GlcNAc (Haran 1996).
$N$-Acetylglucosaminidase plays an important role in the degradation of chitin and is broadly distributed in GH3, GH20, GH83 and GH116 (Ferrara et al. 2014). This scenario is also true for CS1801, which harbors 7 genes from GH18 and 2 genes from GH19, including chitinases. Among GTs, the major subcategory was GT87, followed by GT43. Among CBMs, the major category was CBM13, followed by CBM5, CBM12 and CBM32. Among CEs, the major subcategory was CE7, followed by CE10 and CE4. Chitin deacetylase converts chitin to chitosan and is a member of the carbohydrate esterase family 4 (CE4) defined in the CAZy database (Park et al. 2010). In the CS1801 genome, CBM2, CBM5, CBM12, CBM37 and CBM50, which have affinity for chitin, were also detected (http://www.cazy.org/Carbohydrate-Binding-Modul es.html: Park et al. 2010).

\section{CARD analysis}

A total of 63 AR proteins in S. diastaticus CS1801 were predicted, including DNA gyrase subunit $B$, the daunorubicin doxorubicin resistance ATP-binding protein DrrA, a $\beta$-lactamase precursor, virginiamycin B lyase, the quaternary ammonium compound-resistance protein

Table 3 Carbohydrate-active enzyme counts of Streptomyces diastaticus CS1801

\begin{tabular}{|c|c|c|c|c|c|c|c|}
\hline CAZy & Count & CAZy & Count & CAZy & Count & CAZy & Count \\
\hline AA1 & 2 & CE1 & 15 & GH39 & 1 & GT7 & 1 \\
\hline AA3 & 12 & CE3 & 6 & $\mathrm{GH} 42$ & 1 & GT9 & 2 \\
\hline AA4 & 5 & CE4 & 10 & $\mathrm{GH} 46$ & 1 & GT12 & 3 \\
\hline AA5 & 3 & CE7 & 12 & GH55 & 1 & GT2_ & 2 \\
\hline AA6 & 1 & CE8 & 1 & GH57 & 2 & GT20 & 1 \\
\hline AA7 & 7 & CE9 & 9 & GH63 & 2 & GT21 & 5 \\
\hline AA8 & 7 & CE10 & 11 & GH64 & 1 & GT27 & 5 \\
\hline AA10 & 2 & CE14 & 4 & GH65 & 4 & GT28 & 4 \\
\hline CBM2 & 2 & $\mathrm{GH1}$ & 5 & GH74 & 1 & GT35 & 2 \\
\hline CBM3 & 1 & $\mathrm{GH} 2$ & 3 & $\mathrm{GH} 77$ & 1 & GT39 & 1 \\
\hline CBM5 & 3 & $\mathrm{GH} 3$ & 3 & GH78 & 3 & GT41 & 11 \\
\hline CBM6 & 1 & $\mathrm{GH} 4$ & 1 & GH81 & 2 & GT45 & 2 \\
\hline CBM12 & 3 & $\mathrm{GH} 5$ & 2 & GH84 & 4 & GT50 & 1 \\
\hline CBM13 & 4 & GH6 & 3 & GH87 & 1 & GT51 & 4 \\
\hline CBM16 & 1 & GH13 & 11 & GH93 & 1 & GT76 & 1 \\
\hline CBM20 & 1 & GH15 & 7 & GH95 & 2 & GT81 & 5 \\
\hline CBM32 & 3 & GH16 & 1 & GH103 & 2 & GT83 & 3 \\
\hline CBM36 & 1 & GH18 & 7 & GH109 & 4 & GT87 & 14 \\
\hline CBM37 & 1 & GH19 & 2 & GH114 & 1 & PL6 & 1 \\
\hline CBM42 & 1 & $\mathrm{GH} 20$ & 3 & GH119 & 4 & PL9 & 1 \\
\hline CBM47 & 1 & $\mathrm{GH} 23$ & 7 & GH135 & 1 & PL10 & 1 \\
\hline CBM48 & 2 & $\mathrm{GH} 25$ & 4 & GT1 & 4 & PL11 & 2 \\
\hline CBM50 & 2 & GH31 & 1 & GT2 & 14 & PL22 & 1 \\
\hline CBM51 & 1 & GH33 & 2 & GT4 & 11 & & \\
\hline CBM66 & 1 & GH35 & 1 & GT5 & 11 & & \\
\hline
\end{tabular}


SugE and other antibiotic resistance proteins. In addition, CS1801 has two kinds of resistance proteins, aminoglycoside/hydroxyurea antibiotic resistance kinase (EC 2.7.1.72) and UDP-GlcNAc 1-carboxyvinyltransferase (EC 2.5.1.7), which may be closely related to COS inhibition in the late fermentation stage.

\section{Analysis of enzymes involved in the metabolism of chitin} Both the fermentation products and the whole-genome data of CS1801 aid in elucidating the chitin degradation, metabolism and synthesis mechanisms. The most important phenotypic property of the CS1801 strain is its ability to efficiently hydrolyze chitin and utilize it as a growth substrate. CS1801 contains various genes encoding specific enzymes with chitin hydrolysis activity, such as 9 chitinases, $5 \mathrm{~N}$-acetylglucosaminidases, 10 chitin deacetylases, $4 \beta$-galactosidases, $7 \beta$-glucosidases and 1 chitosanase. In addition, CS1801 contains a variety of enzymes that are thought to be involved in chitin synthesis. Details of the enzymes are listed in Table 4.

\section{Discussion}

The results of fermentation revealed that $S$. diastaticus CS1801 can convert the chitin derived from crab shells, colloidal chitin and $\mathrm{N}$-acetylglucosamine to COS. To explore the mechanism of the chitin degradation process, we performed a genome-wide analysis of the CS1801 strain and found a large number of genes related to enzymatic hydrolysis of COS, the most important of which is chitinase. The predicted chitin degradation and synthesis pathways of CS1801 are proposed in Fig. 4. CS1801 degrades chitin through three predicted pathways as follows: (i) endochitinase hydrolyzes the insoluble form of chitin to water-soluble oligomers, especially $(\mathrm{GlcNAc})_{2}$, and then, $(\mathrm{GlcN})_{2}$ is generated from $(\mathrm{GlcNAc})_{2}$ by chitin deacetylase. (ii) GlcNAc is ultimately produced from chitin by exochitinase, and GlcNAc is transformed to GlcN by chitin deacetylase. (iii) Chitosan is generated from chitin by chitin deacetylase and then is transformed to COS by chitosanase (Seki et al. 2019). All of the (GlcN) molecules are transformed to GlcN by $\beta$-galactosidase or $\beta$-glucosidase. $\beta$-Galactosidase and $\beta$-glucosidase split the $\beta$-(1,4)-glycosidic bond of $(\mathrm{GlcN})_{2}$ to generate GlcN (Chinchetru et al. 1989; Sorokin et al. 2014). Then, GlcN is transformed to 6-phosphate-GlcN by glucokinase (Sorokin et al. 2014), GlcN-6-phosphate deaminase (EC 3.5.99.6) transforms 6-phosphate-GlcN to 6-phosphatefructose, and finally, $\mathrm{CO}_{2}$ and $\mathrm{H}_{2} \mathrm{O}$ are formed by the action of the EMP, HMS and TCA cycles. In this unique manner, CS1801 can synthesize chitin. First, GlcN6-phosphate-fructose aminotransferase (isomerization) transforms 6-phosphate-fructose to 6-phosphate-GlcN (Leriche et al. 1997). Then, 6-phosphate-GlcN is transformed to GlcN-1-phosphate by phosphoglucosamine mutase (Shimazu et al. 2012). N-GlcNAc-1-phosphate is formed by GlcN-1-phosphate $N$-acetyltransferase, which transforms GlcN-1-phosphate to N-GlcNAc-1-phosphate (Zhang et al. 2015). Next, UDP-N-GlcNAc is formed by UDP-N-GlcNAc pyrophosphorylase, which can transform $N$-GlcNAc-1-phosphate to UDP-N-GlcNAc

\section{Table 4 Genes encoding enzymes involved in chitin metabolism}

\begin{tabular}{|c|c|c|c|}
\hline Number & Predicted genes & EC & Activity \\
\hline 1 & $\begin{array}{l}\text { PROKKA01070, 02558, 05523, 05524, 05525, 05527, } \\
\quad 05918,07311,07336\end{array}$ & $\mathrm{EC}: 3.2 .1 .14$ & Chitinase \\
\hline 2 & PROKKA02420, 05378, 02684, 05073, 05074 & EC: 3.2.1.52 & N-Acetylglucosaminidase \\
\hline 3 & $\begin{array}{l}\text { PROKKA00813, 01449, 02821, 03087, 05050, 05463, } \\
\text { 06475, 06684, 06832, } 07353\end{array}$ & EC: 3.1.1.72/EC: 3.5 .1 .41 & Acetyl xylan esterase/chitin deacetylase \\
\hline 4 & PROKKA05224, 05225, 06460, 07087 & $\mathrm{EC}: 3.2 .1 .23$ & $\beta$-Galactosidase \\
\hline 5 & $\begin{array}{l}\text { PROKKA00858, 02420, 02486, 04829, 04830, 05378, } \\
\quad 06458\end{array}$ & EC: 3.2.1.21 & $\beta$-Glucosidase \\
\hline 6 & PROKKA01722 & $\mathrm{EC}: 3.2 .1 .132$ & Chitosanase \\
\hline 7 & PROKKA01398, 02174 & EC: 2.7 .1 .12 & Glucokinase \\
\hline 8 & PROKKA02470, 02853, 04321 & $\mathrm{EC}: 2.6 .1 .16$ & $\begin{array}{l}\text { GlcN-fructose-6-phosphate aminotransferase (isomeri- } \\
\text { zation) }\end{array}$ \\
\hline 9 & PROKKA02857 & EC: 5.4 .2 .10 & Phosphoglucosamine mutase \\
\hline 10 & PROKKA04318 & $\mathrm{EC}: 3.5 .99 .6$ & GlcN-6-phosphate deaminase \\
\hline 11 & PROKKA04700 & EC: $2.3 .1 .157 / E C: 2.7 .7 .23$ & $\begin{array}{l}\text { GlcN-1-phosphate N-acetyltransferase/UDP-N-GlcNAc } \\
\text { pyrophosphorylase }\end{array}$ \\
\hline 12 & $\begin{array}{l}\text { PROKKA00223, 01062, 01446, 04349, 04925, 04958, } \\
05020,05024,05028,05050,05156,05590,06114 \\
06196\end{array}$ & EC: 2.4.1.12/EC: 2.4.1.16 & Cellulose synthase/chitin synthase \\
\hline
\end{tabular}




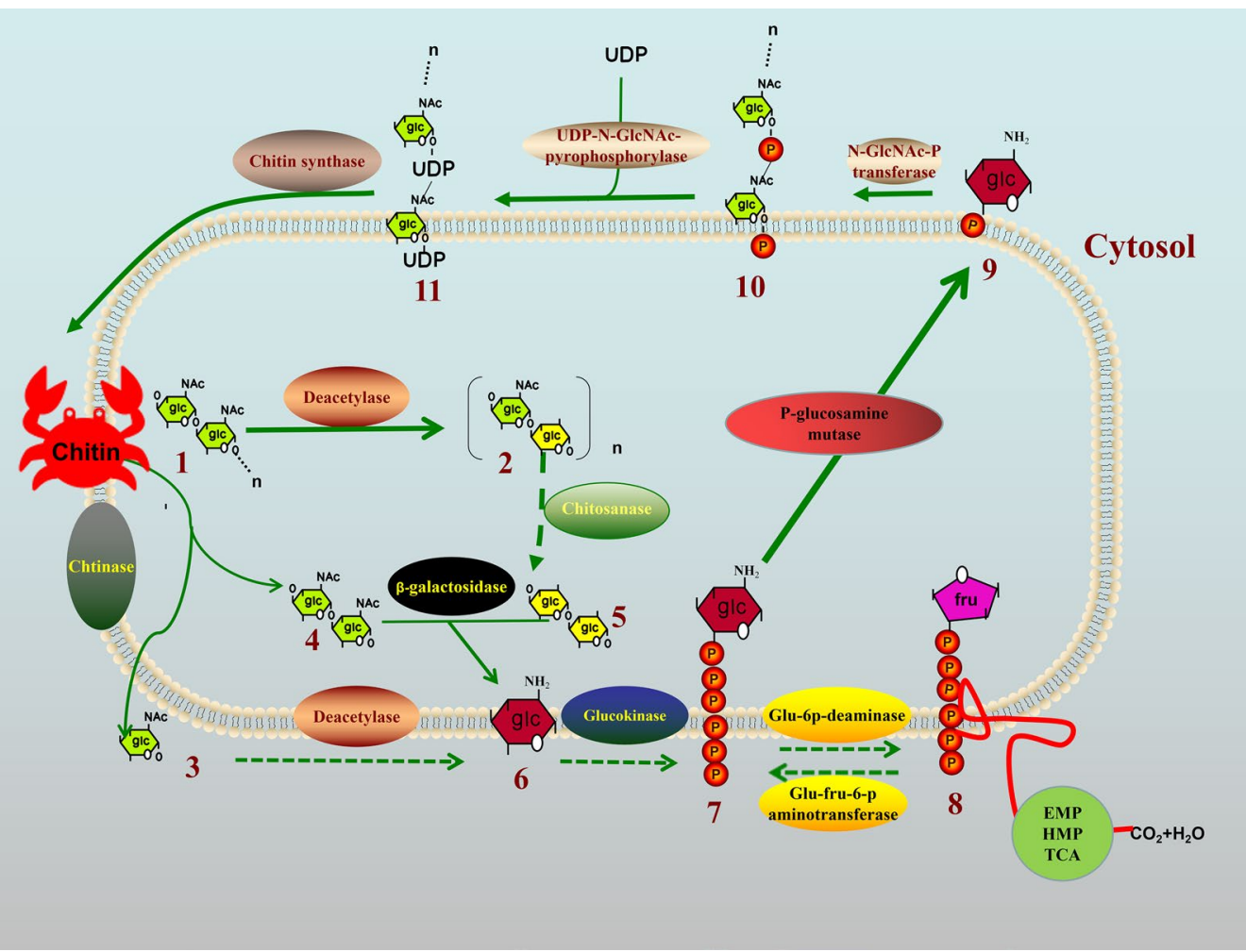

Fig. 4 Proposed chitin degradation and synthesis pathways of CS1801. 1: Chitin; 2: chitosan; 3: GlcNAc; 4: (GlcNAc) 2; 5: (GlcN) $;$ 6: GlcN; 7: 6-phosphate-GIcN; 8: 6-phosphate-fructose; 9: GlcN-1-phosphate; 10: N-GlcNAc-1-phosphate; 11: UDP-N-GIcNAc

(Ullrich and van Putten 1995). Finally, chitin is produced by poly- $\beta-1,6-N$-acetyl-D-GlcN synthase (chitin synthase) (Sburlati and Cabib 1986).

CS1801 can hydrolyze colloidal chitin to $(\mathrm{GlcN})_{2}$, $(\mathrm{GlcN})_{3},(\mathrm{GlcN})_{4}$ and $(\mathrm{GlcN})_{5}$. It can also synthesize $(\mathrm{GlcN})_{3},(\mathrm{GlcN})_{4}$ and $(\mathrm{GlcN})_{5}$ from GlcNAc. According to these findings, CS1801 has the complete metabolic pathway for chitin, including hydrolysis and synthesis. Streptomyces coelicolor A3 (2) is a well-studied Streptomyces strain that has a known whole-genome sequence (Bentley et al. 2002) containing 13 chitinase genes (some of which are putative). However, CS1801 has 9 chitinases, 1 chitosanase and 7 potential chitinases (PROKKA00833, 02567, 02568, 05526, 05528, 06351, and 07303) with binding domains associated with chitin degradation. Chitinivibrio alkaliphilus gen. nov., sp. nov. is a novel extremely haloalkaliphilic anaerobe that has fewer than 5 chitinases (Sorokin et al. 2014). CS1801 has more chitinases than other strains and a more complete chitin metabolism pathway.

CS1801 can directly convert untreated crab shell waste to $\operatorname{COS}$ with a molecular weight less than $1000 \mathrm{Da}$, which has good commercial application value (Chen et al. 2003, 2005). To further study the mechanism of CS1801-mediated chitin degradation, the enzymes in the reaction pathway will be cloned and expressed in subsequent work, and directed evolution can be used to control the degree of chitin hydrolysis. Finally, a COS with single polymerization and acetylation can be obtained with improved purity. In general, CS1801 is a very interesting strain, and CS1801 or its enzymes have the potential to produce COSs. This study will lay a good foundation for industrial COS production and increase the added value of waste, such as crab shells.

\section{Abbreviations}

COS: Chitooligosaccharide; COG: Cluster of Orthologous Groups database; GO: Gene Ontology functional database; KEGG: Kyoto Encyclopedia of Genes and Genomes pathway database; CAZy: Carbohydrate-active enzymes; CARD: Comprehensive Antibiotic Resistance Database; AA: Auxiliary activity; GH: Glycosyl hydrolase; CBM: Carbohydrate-binding module; CE: Carbohydrate esterase; GT: Glycosyl transferase; PL: Polysaccharide lyase; GICNAc: N-acetylglucosamine; GlcN: Glucosamine.

\section{Acknowledgements}

The authors have no acknowledgments.

\section{Authors' contributions}

$B Q$ and $L W$ designed the study and performed the experiments; TX and MQ performed the experiments, analyzed the data, and wrote the manuscript; $\mathrm{HL}$ 
analyzed the data and wrote the manuscript; and DC and CX performed the experiments. All authors read and approved the final manuscript.

\section{Funding}

This study was supported by the Jiangsu Provincial Key Research and Development Program (China) (BE2017316, BE2017326, and BE2018320) and the Suzhou Science and Technology Project (China) (SS201818).

\section{Availability of data and materials}

The data used to support the findings of this study are included within the article.

\section{Ethics approval and consent to participate}

Not applicable.

\section{Consent for publication}

Not applicable.

\section{Competing interests}

The authors declare that they have no competing interests.

\section{Author details}

${ }^{1}$ Research Center of Fermentation Engineering, Changshu Institute of Technology, Changshu 215500, China. ${ }^{2}$ College of Pharmaceutical Science, Soochow University, Suzhou 215123, China. ${ }^{3}$ Department of Biological Science, Xi'an Jiaotong-Liverpool University, Suzhou 215123, China. ${ }^{4}$ School of Food Science and Technology, Jiangnan University, Wuxi 214122, China.

Received: 26 July 2019 Accepted: 23 January 2020

Published online: 08 February 2020

\section{References}

Bentley SD, Chater KF, Cerdeno-Tarraga AM, Challis GL, Thomson NR, James KD, Harris DE, Quail MA, Kieser H, Harper D, Bateman A, Brown S, Chandra G, Chen CW, Collins M, Cronin A, Fraser A, Goble A, Hidalgo J, Hornsby T, Howarth S, Huang CH, Kieser T, Larke L, Murphy L, Oliver K, O'Neil S, Rabbinowitsch E, Rajandream MA, Rutherford K, Rutter S, Seeger K, Saunders D, Sharp S, Squares R, Squares S, Taylor K, Warren T, Wietzorrek A, Woodward J, Barrell BG, Parkhill J, Hopwood DA (2002) Complete genome sequence of the model actinomycete Streptomyces coelicolor A3(2). Nature 417:141-147

Cao R, Zhao Y, Zhou Z, Zhao X (2018) Enhancement of the water solubility and antioxidant activity of hesperidin by chitooligosaccharide. J Sci Food Agric 98:2422-2427

Chen AS, Taguchi T, Sakai K, Kikuchi K, Wang MW, Miwa I (2003) Antioxidant activities of chitobiose and chitotriose. Biol Pharm Bull 26:1326-1330

Chen AS, Taguchi T, Okamoto H, Danjo K, Sakai K, Matahira Y, Wang MW, Miwa I (2005) Pharmacokinetics of chitobiose and chitotriose administered intravenously or orally to rats. Biol Pharm Bull 28:545-548

Chinchetru MA, Cabezas JA, Calvo P (1989) Purification and characterization of a broad specificity beta-glucosidase from sheep liver. Int J Biochem 21:469-476

Durairaj K, Velmurugan P, Park JH, Chang WS, Park YJ, Senthilkumar P, Choi KM, Lee JH, Oh BT (2017) Potential for plant biocontrol activity of isolated Pseudomonas aeruginosa and Bacillus stratosphericus strains against bacterial pathogens acting through both induced plant resistance and direct antagonism. FEMS Microbiol Lett 364:fn×225

Einbu A, Grasdalen H, Varum KM (2007) Kinetics of hydrolysis of chitin/ chitosan oligomers in concentrated hydrochloric acid. Carbohydr Res 342:1055-1062

Fang IM, Yang CM, Yang CH (2015) Chitosan oligosaccharides prevented retinal ischemia and reperfusion injury via reduced oxidative stress and inflammation in rats. Exp Eye Res 130:38-50

Ferrara MC, Cobucci-Ponzano B, Carpentieri A, Henrissat B, Rossi M, Amoresano A, Moracci M (2014) The identification and molecular characterization of the first archaeal bifunctional exo-beta-glucosidase/N-acetyl-beta-glucosaminidase demonstrate that family GH116 is made of three functionally distinct subfamilies. Biochim Biophys Acta 1840:367-377
Guo N, Sun J, Wang W, Gao L, Liu J, Liu Z, Xue C, Mao X (2019) Cloning, expression and characterization of a novel chitosanase from Streptomyces albolongus ATCC 27414. Food Chem 286:696-702

Hamdi M, Hammami A, Hajji S, Jridi M, Nasri M, Nasri R (2017) Chitin extraction from blue crab (Portunus segnis) and shrimp (Penaeus kerathurus) shells using digestive alkaline proteases from P. segnis viscera. Int J Biol Macromol 101:455-463

Hara M, Sugimoto H, Uemura M, Akagi K, Suzuki K, Ikegami T, Watanabe T (2013) Involvement of Gln679, in addition to Trp687, in chitin-binding activity of the chitin-binding domain of chitinase A1 from Bacillus circulans WL-12. J Biochem 154:185-193

Haran S (1996) Differential expression of Trichoderma harzianum chitinases during mycoparasitism. Phytopathology 86:980-985

Ilangumaran G, Stratton G, Ravichandran S, Shukla PS, Potin P, Asiedu S, Prithiviraj B (2017) Microbial degradation of lobster shells to extract chitin derivatives for plant disease management. Front Microbiol 8:781

Jiang Y, Fu C, Liu G, Guo J, Su Z (2018) Cholesterol-lowering effects and potential mechanisms of chitooligosaccharide capsules in hyperlipidemic rats. Food Nutr Res 62:1446

Jung DH, Chung WH, Seo DH, Nam YD, Yoon S, Park CS (2018) Complete genome sequence of Bifidobacterium choerinum FMB-1, a resistant starch-degrading bacterium. J Biotechnol 274:28-32

Kanehisa M, Goto S (2000) KEGG: kyoto encyclopedia of genes and genomes. Nucleic Acids Res 28:27-30

Kidibule PE, Santos-Moriano P, Jimenez-Ortega E, Ramirez-Escudero M, Limon MC, Remacha M, Plou FJ, Sanz-Aparicio J, Fernandez-Lobato M (2018) Use of chitin and chitosan to produce new chitooligosaccharides by chitinase Chit42: enzymatic activity and structural basis of protein specificity. Microb Cell Fact 17:47

Lan W, Wang W, Yu Z, Qin Y, Luan J, Li X (2016) Enhanced germination of barley (Hordeum vulgare L.) using chitooligosaccharide as an elicitor in seed priming to improve malt quality. Biotechnol Lett 38:1935-1940

Le B, Yang SH (2018) Characterization of a chitinase from Salinivibrio sp. BAO-1801 as an antifungal activity and a biocatalyst for producing chitobiose. J Basic Microbiol 58:848-856

Lee HW, Park YS, Jung JS, Shin WS (2002) Chitosan oligosaccharides, dp 2-8, have prebiotic effect on the Bifidobacterium bifidium and Lactobacillus sp. Anaerobe 8:319-324

Leriche C, Badet-Denisot MA, Badet B (1997) Affinity labeling of Escherichia coli glucosamine-6-phosphate synthase with a fructose 6-phosphate analog-evidence for proximity between the $\mathrm{N}$-terminal cysteine and the fructose-6-phosphate-binding site. Eur J Biochem 245:418-422

Li K, Liu S, Xing R, Qin Y, Li P (2013) Preparation, characterization and antioxidant activity of two partially $\mathrm{N}$-acetylated chitotrioses. Carbohydr Polym 92:1730-1736

Liang S, Sun Y, Dai X (2018) A review of the preparation, analysis and biological functions of chitooligosaccharide. Int J Mol Sci 19:E2197

Lin S, Qin Z, Chen Q, Fan L, Zhou J, Zhao L (2019) Efficient immobilization of bacterial GH family 46 chitosanase by carbohydrate-binding module fusion for the controllable preparation of chitooligosaccharides. J Agric Food Chem 67:6847-6855

Liu YL, Jiang S, Ke ZM, Wu HS, Chi CW, Guo ZY (2009) Recombinant expression of a chitosanase and its application in chitosan oligosaccharide production. Carbohydr Res 344:815-819

Lombard V, Ramulu HG, Drula E, Coutinho PM, Henrissat B (2014) The carbohydrate-active enzymes database (CAZy) in 2013. Nucleic Acids Res 42:D490-D495

McArthur AG, Waglechner N, Nizam F, Yan A, Azad MA, Baylay AJ, Bhullar K, Canova MJ, De Pascale G, Ejim L, Kalan L, King AM, Koteva K, Morar M, Mulvey MR, O'Brien JS, Pawlowski AC, Piddock LJ, Spanogiannopoulos P, Sutherland AD, Tang I, Taylor PL, Thaker M, Wang W, Yan M, Yu T, Wright GD (2013) The comprehensive antibiotic resistance database. Antimicrob Agents Chemother 57:3348-3357

Moon C, Seo DJ, Song YS, Hong SH, Choi SH, Jung WJ (2017) Antifungal activity and patterns of $\mathrm{N}$-acetyl-chitooligosaccharide degradation via chitinase produced from Serratia marcescens PRNK-1. Microb Pathog 113:218-224

Nandhini D, Somasundaram E, Amanullah KM (2017) Effect of rhizobial nod factors (lipochitooligosaccharide) on seedling growth of blackgram under salt stress. Legume Res 41:159-162 
Nazari B, Saito A, Kobayashi M, Miyashita K, Wang Y, Fujii T (2011) High expression levels of chitinase genes in Streptomyces coelicolor A3(2) grown in soil. FEMS Microbiol Ecol 77:623-635

Nguyen-Thi N, Doucet N (2016) Combining chitinase C and N-acetylhexosaminidase from Streptomyces coelicolor A3(2) provides an efficient way to synthesize $\mathrm{N}$-acetylglucosamine from crystalline chitin. J Biotechnol 220:25-32

Park BH, Karpinets TV, Syed MH, Leuze MR, Uberbacher EC (2010) CAZymes analysis toolkit (CAT): web service for searching and analyzing carbohydrate-active enzymes in a newly sequenced organism using CAZy database. Glycobiology 20:1574-1584

Rinaudo M (2006) Chitin and chitosan: properties and applications. Prog Poly Sci 31:603-632

Sburlati A, Cabib E (1986) Chitin synthetase 2, a presumptive participant in septum formation in Saccharomyces cerevisiae. J Biol Chem 261:15147-15152

Seki K, Nishiyama Y, Mitsutomi M (2019) Characterization of a novel exochitosanase, an exo-chitobiohydrolase, from Gongronella butleri. J Biosci Bioeng 127:425-429

Shenghe L, Erhui J, Enmei Q, Guozhong W, Kui L (2017) Chitooligosaccharide promotes immune organ development in broiler chickens and reduces serum lipid levels. Histol Histopathol 32:951-961

Shimazu K, Takahashi Y, Karibe H, Mitsuhashi F, Konishi K (2012) Contribution of phosphoglucosamine mutase to determination of bacterial cell morphology in Streptococcus gordonii. Odontology 100:28-33

Sorokin DY, Gumerov VM, Rakitin AL, Beletsky AV, Damste JS, Muyzer G, Mardanov AV, Ravin NV (2014) Genome analysis of Chitinivibrio alkaliphilus gen. nov., sp. nov., a novel extremely haloalkaliphilic anaerobic chitinolytic bacterium from the candidate phylum termite group 3. Environ Microbiol 16:1549-1565

Suma K, Podile AR (2013) Chitinase A from Stenotrophomonas maltophilia shows transglycosylation and antifungal activities. Bioresour Technol 133:213-220

Sun G, Yang Q, Zhang A, Guo J, Liu X, Wang Y, Ma Q (2018) Synergistic effect of the combined bio-fungicides epsilon-poly-L-lysine and chitooligosaccharide in controlling grey mould (Botrytis cinerea) in tomatoes. Int J Food Microbiol 276:46-53

Swiatkiewicz S, Swiatkiewicz M, Arczewska-Wlosek A, Jozefiak D (2015) Chitosan and its oligosaccharide derivatives (chito-oligosaccharides) as feed supplements in poultry and swine nutrition. J Anim Physiol Anim Nutr (Berl) 99:1-12

Takashima T, Ohnuma T, Fukamizo T (2018) NMR analysis of substrate binding to a two-domain chitinase: comparison between soluble and insoluble chitins. Carbohydr Res 458-459:52-59

Tatusov RL, Galperin MY, Natale DA, Koonin EV (2000) The COG database: a too for genome-scale analysis of protein functions and evolution. Nucleic Acids Res 28:33-36

Ullrich J, van Putten JP (1995) Identification of the gonococcal glmU gene encoding the enzyme $\mathrm{N}$-acetylglucosamine 1-phosphate uridyltransferase involved in the synthesis of UDP-GICNAC. J Bacteriol 177:6902-6909

Xu TT, Chen B, Hou SY, Cao D, Xu CL, Qi B (2019) Screening, identification of chitinase producing strains and analysis of enzymaticproduct. Food Sci 40:207-212.http://www.spkx.net.cn/CN/abstract/abstract49165.shtml

Yadav S, Dubey SK (2018) Cellulose degradation potential of Paenibacillus lautus strain BHU3 and its whole genome sequence. Bioresour Technol 262:124-131

Zhang Z, Shimizu Y, Kawarabayasi Y (2015) Characterization of the amino acid residues mediating the unique amino-sugar-1-phosphate acetyltransferase activity of the archaeal ST0452 protein. Extremophiles 19:417-427

Zhang A, He Y, Wei G, Zhou J, Dong W, Chen K, Ouyang P (2018) Molecular characterization of a novel chitinase $\mathrm{CmChi1}$ from Chitinolyticbacter meiyuanensis SYBC-H1 and its use in N-acetyl-D-glucosamine production. Biotechnol Biofuels 11:179

Zhao L, Sun T, Wang L (2017) Chitosan oligosaccharide improves the therapeutic efficacy of sitagliptin for the therapy of Chinese elderly patients with type 2 diabetes mellitus. Ther Clin Risk Manag 13:739-750

Zhou Q, Cui L, Ren L, Wang P, Deng C, Wang Q, Fan X (2018) Preparation of a multifunctional fibroin-based biomaterial via laccase-assisted grafting of chitooligosaccharide. Int J Biol Macromol 113:1062-1072

Zou P, Li K, Liu S, Xing R, Qin Y, Yu H, Zhou M, Li P (2015) Effect of chitooligosaccharides with different degrees of acetylation on wheat seedlings under salt stress. Carbohydr Polym 126:62-69

\section{Publisher's Note}

Springer Nature remains neutral with regard to jurisdictional claims in published maps and institutional affiliations.

\section{Submit your manuscript to a SpringerOpen ${ }^{\circ}$ journal and benefit from:}

- Convenient online submission

- Rigorous peer review

- Open access: articles freely available online

- High visibility within the field

- Retaining the copyright to your article

Submit your next manuscript at springeropen.com 